\title{
Article \\ Impact of Adenosine A2 Receptor Ligands on BCL2 Expression in Skeletal Muscle Cells
}

\author{
Mansour Haddad
}

check for

updates

Citation: Haddad, M. Impact of Adenosine A2 Receptor Ligands on BCL2 Expression in Skeletal Muscle Cells. Appl. Sci. 2021, 11, 2272. https://doi.org/10.3390/app11052272

Academic Editor: Nadia Lotti

Received: 18 January 2021

Accepted: 22 February 2021

Published: 4 March 2021

Publisher's Note: MDPI stays neutral with regard to jurisdictional claims in published maps and institutional affiliations.

Copyright: (C) 2021 by the author. Licensee MDPI, Basel, Switzerland. This article is an open access article distributed under the terms and conditions of the Creative Commons Attribution (CC BY) license (https:/ / creativecommons.org/licenses/by/ $4.0 /)$.
Faculty of Pharmacy, Philadelphia University, Amman 19392, Jordan; Dr.man.haddad@gmail.com

Simple Summary: This study discovered the potential anti-apoptotic effect for CGS21680, a selective adenosine A2A receptor agonist, which can be beneficial for the treatment of apoptosis-related skeletal muscle dysfunctions. Indeed, this novel study demonstrated that CGS21680 induced changes on a molecular level (BCL2) in skeletal muscle, which can potentially prevent apoptosis and atrophy of the muscle. These findings provide a novel mechanism whereby adenosine A2 receptor ligands, including CGS21680, might act as an anti-apoptotic mediator in skeletal muscle tissues. This study could help pharmaceutical researchers to uncover safer drugs that might prevent apoptosis for skeletal muscle diseases. The study provides a future direction for medical and pharmaceutical applications of adenosine A2 receptor ligands in improvising current therapies used in the treatment of skeletal muscle atrophy. In fact, this study will help researchers to uncover the critical areas of adenosine A2 receptors on skeletal muscle cells apoptosis, which many researchers have not yet explored. Thus, a new theory on these receptors may established.

Abstract: Background: Adenosine plays the role of regulating cell differentiation, proliferation, and apoptosis in various kinds of cells through the B-cell lymphoma 2 (BCL2) pathway. Objectives: Since anti-apoptotic (BCL2) expression plays a role in controlling apoptosis in some cell lines, this study was designed to investigate whether adenosine analogue, NECA (non-selective adenosine receptors agonist), selective adenosine A2B receptor antagonist, PSB 603, and a selective adenosine A2A receptor agonist, CG21680, affect BCL2-gene expression in the skeletal muscle cells of rats. The purpose of this investigation was to test the hypothesis that CG21680 treatment would significantly intensify BCL2 gene expression in rat skeletal muscle. Methods: Flasks measuring $25 \mathrm{~cm}^{2}$ were employed in culturing the rat L6 skeletal muscle cells. After treating these differential cells, the relative mRNA expression level for the BCL2 gene, at varying conditions of treatment, was measured using quantitative reverse transcription-polymerase chain reaction (qRT-PCR). Results: From the qRTPCR analysis results, it was concluded that BCL2 expression was markedly amplified after selective adenosine A2A receptor agonist, CGS21680 $(p<0.01)$ treatment. More prospective validation for the adenosine receptors' contribution in modulating apoptosis by NECA was delivered by the outcomes from the combined pre-treatment of the cells with NECA and PSB 603. These outcomes show that when starved skeletal muscle cells are treated with a combination of NECA and 100 nM PSB 603, there was a substantial decrease in comparison to either treatment used on its own. Conclusions: This study's results showed, for the first time, an increase in BCL2 gene expression within skeletal muscle after CGS21680 treatment. Hence, the prospective escalation in BCL2 protein expression might have a protective role to play against apoptosis and avert damage to the skeletal muscle.

Keywords: NECA; CGS21680; PSB 603; insulin; skeletal muscle cells; mRNA gene expression; BCL2 and apoptosis

\section{Introduction}

Several factors contribute towards the apoptotic mechanisms' intricacy in skeletal muscle tissue [1,2]. These factors include (1) variant morphological and biochemical mitochondrial pools within skeletal muscle fiber types and (2) multinucleated muscle 
cells. Thus, it is observed that, with regard to apoptosis, the skeletal muscle represents a distinctive tissue. Moreover, in both myoblast and myotube cells the apoptotic process in skeletal muscle was suggested to be an event of natural development and has also been observed in several diseases, like Duchenne muscular dystrophy [3], to constitute an essential feature in skeletal muscle fibers.

Within a cell death pathway, an anti-apoptotic protein, i.e., B-cell lymphoma 2 (BCL2), functions as a critical intracellular apoptosis checkpoint, which effectively subdues apoptosis in response to a variety of stimuli (death antagonist) [4]. According to a host of studies, apoptosis was inhibited by BCL2 expression, which in skeletal muscle cells [5] also identified an early stage of myogenesis. In addition, skeletal muscle cell apoptosis could ameliorate BCL2 family expression. Moreover, according to research, BCL2 expression was suggested to be imperative for large numbers of muscle cell regeneration as well as long-term muscle progenitor cell survival [6]. In skeletal muscle apoptosis, the potential importance of BCL2 expression was also demonstrated by several studies; for example, in aging tissue, as a suggested apoptosis mechanism, an age-associated BCL2 level decrease was suspected [7]. In addition, muscle cell apoptosis has been reported by other studies, evidencing the selective targeting of a BCL2-deficient one in differentiating murine myotubes [8]. Previous studies demonstrated adenosine and adenosine analogue to have a regulatory effect on apoptosis of several types of cells, for instance, human thymocytes, rat brain astrocytes, and lymphoid cells. This was evident in two independent pathways, namely, adenosine transport or/and extracellular receptor subtype activity modulations [9-12].

It was observed that the adenosine receptors, in fact, present the possibility of serving as potential cytoprotective receptors, and thus notably warrant supplementary research, particularly in the context of ameliorating skeletal muscle injury [13]. Moreover, a specific dearth in research was evident in the adenosine receptor effects in myotubes culture [14,15]. Correspondingly, adenosine A2A receptors can be considered as new cytoprotective receptors [16], albeit warranting further investigation for skeletal muscle injury amelioration.

However, the apoptosis impact on degradation of skeletal muscle is still ambiguous; thus, it was intriguing to study, in skeletal muscle cells, if it was possible for adenosine or adenosine analogue or related ligands to modulate anti-apoptotic (BCL2) gene expression [6]. This further presented the probability of muscle cell apoptosis inhibition, and a consequent contribution to the protection of skeletal muscle, cell regeneration or survival [8].

The purpose of this investigation was to test the hypothesis that CG21680, NECA and/or PSB 603 treatment would significantly modulate BCL2 gene expression in rat skeletal muscle.

\section{Materials and Methods}

\subsection{Materials}

Horse serum, antibiotics, L-glutamate and insulin were purchased from Sigma Chemical Company, Germany; Fetal bovine serum (FBS) was provided by Capricorn Scientific, United States of America (USA); TRIzol Reagent and fetal bovine serum stripped of charcoal were provided by Applied Biosystem, San Francisco, CA, USA; and dimethyl sulphoxide (DMSO) reagent was procured from Santa Cruz, CA, USA. Tocris Bioscience, Bristol, UK [10], provided N-Ethylcarboxamido adenosine (NECA); PAA Company, Houston, TX, USA, supplied Ham-F 10; and Caisson, Smithfield, RI, USA, provided Dulbecco's modified essential medium (DMEM). Qiagen, Hilden, Germany, provided one kit of Rotor-Gene SYBR, Green PCR Kit, RNeasy Mini Total RNA Purification kits, and RNase-Free DNase sets. Thermo Scientific Company, Boston, MA, USA, provided RevertAid First Strand complementary DNA (cDNA) Synthesis Kits. 


\subsection{Cell Culture}

Rat L6 myoblast cell lines, which originated from the American Type Culture Collection, were incubated at $37^{\circ} \mathrm{C}$ and $5 \% \mathrm{CO}_{2}$ in Dulbecco's Modified Medium (DMEM, Sigma, Gillingham, UK), high-glucose ( $4500 \mathrm{mg} / \mathrm{L}), 10 \%(v / v)$ heat-inactivated FBS, $1 \%$ L-glutamate, and $1 \%$ streptomycin/penicillin

Rat L6 myoblast cell lines were grown to confluence in $25 \mathrm{~cm}^{2}$ flasks for approximately 14 days, checking for differentiation in order to enable myotube formation and changing the medium twice or three times a week on alternate days in accordance with the protocol indicated in [14,17-19] (Figure 1). Following the occurrence of 70 to $90 \%$ confluent myotubes (about two weeks in culture), the cells were serum-starved by being incubated only in Ham-F for a period of seven days.

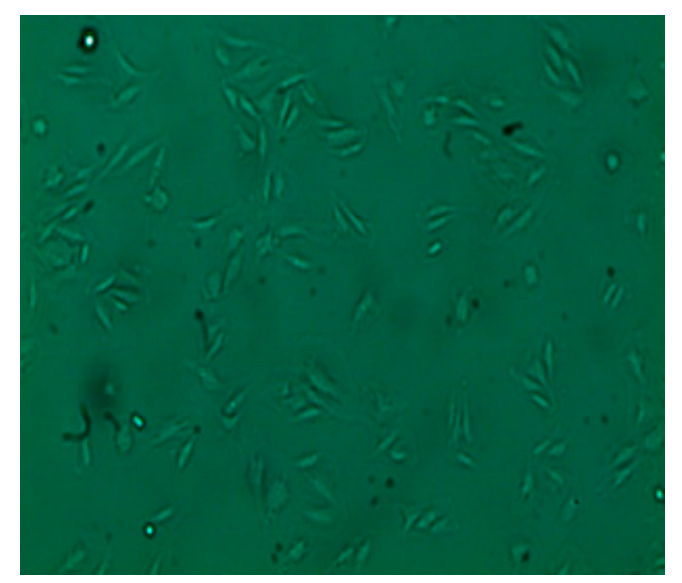

Figure 1. Representative myoblasts derived from passage number 7 myoblasts taken after 1 day seeding into $25 \mathrm{~cm}^{2}(10 \times)$.

\subsection{Experimental Design}

Confluent myotube cells were separated into different conditions, with at least 3 flasks in each condition. Those $70 \%-90 \%$ confluent myotubes (around 2 weeks in culture) (at least $\mathrm{n}=3$ flasks) were serum-starved (Ham-F 10 medium alone) for one week. Then, cells (Figure 2) were treated for one hour with vehicle (0.1\% DMSO), NECA, CGS21680, NECA+PSB 603 (cells were pretreated with PSB 603 for 10 minutes before addition of NECA), or PSB 603 and for 10 minutes with $100 \mathrm{nM}$ insulin (cells were pre-treated with NECA for one hour prior to the addition of insulin). After that, cells were washed with ice cold PBS, then lysed with TRIzol (Invitrogen product name) ( $2 \mathrm{~mL}$ per flask).

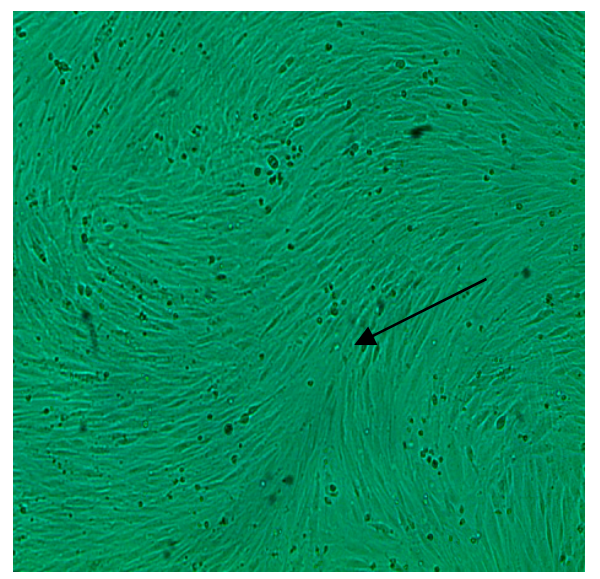

Figure 2. Representative myotubes derived from passage number 7; myotubes taken at (Ham-F10, $1 \% \mathrm{P} / \mathrm{S})$ after 7 days starvation $(10 \times)$. 
The question of whether BCL2 mRNA gene expression in rat L6 skeletal muscle cells could be induced by stimulating adenosine $\mathrm{A} 2$ receptors was addressed by relative quantification by qRT-PCR of NECA's effects using a non-selective adenosine receptor agonist. mRNA gene expression of BCL2 was quantified after starved skeletal muscle cells had been incubated for one hour with NECA $(10 \mu \mathrm{M})$, while the question whether BCL2 mRNA gene expression could be induced in rat L6 skeletal muscle cells by stimulating adenosine A2A receptors was addressed by relative quantification by qRT-PCR of the effect of the selective adenosine receptor agonist CGS21680. mRNA gene expression of BCL2 was quantified after incubation of starved skeletal muscle cells with CGS21680 (100 nM) for one hour. Of note, in the absence of a selective agonist, a selective antagonist to adenosine A2B receptors was used in the form of PSB 603. Its effect was investigated by incubating rat L6 skeletal muscle cells with a combination of PSB 603 and $10 \mu \mathrm{M}$ NECA, the PSB 603 having been added to the cells 10 minutes before the NECA was added. Two separate PSB 603 concentrations were used: $100 \mathrm{nM}$ and $1 \mu \mathrm{M}$.

\subsection{Total RNA Extraction and Reverse Transcription}

L6 skeletal muscle cells were retrieved from rats and stored in $2 \mathrm{~mL}$ of ice-cold TRIzol (Applied Biosystems, USA). In accordance with the TRIzol manufacturer's guidelines, total RNA was extracted from the cells. Using RNeasy purification columns, RNA was cleaned up and on-column DNAse digestion was carried out. A spectrophotometer (JENWAY Genova Nano) was used to determine the concentration and purity of RNA. Then, using 500 ng of total RNA and RevertAid First Strand cDNA Synthesis, reverse transcription was performed.

\subsection{Quantitative Real-Time PCR}

To measure gene expression, quantitative real-time PCR (qRT-PCR) was used, which applied the relative standard curve method. Primers were obtained from Integrated DNA Technologies, Inc., Coralville, IA, USA; these were designed for use with Primer Express software (Applied Biosystems, USA) (Table 1). Each assay was repeated three times using the protocol described by $[15,20-22]$. The average threshold value of each assay repetition was calculated; then, using the standard curve method, the expression of each gene was quantified in relation to the reference gene.

Table 1. List of gene primer sequences.

\begin{tabular}{ccc}
\hline Gene & Sequences $\left(5^{\prime} \rightarrow \mathbf{3}^{\prime}\right)$ & Amplicon Size (bp) \\
\hline \multirow{2}{*}{ BCL2 } & $\begin{array}{c}\text { Forward Primer: } 5^{\prime} \text {-TCGCGACTTTGCAGAGATGTCC-3' } \\
\text { Reverse Primer: 5'-ACCCCATCCCTGAAGAGTTCCT-3' }\end{array}$ & 99 \\
\hline \multirow{2}{*}{ TATA-BOX } & $\begin{array}{c}\text { Forward Primer 5'-TTCGTGCCAGAAATGCTGAA-3' } \\
\text { Reverse Primer 5'-GTTCGTGGCTCTCTTATTCTCATG-3' }\end{array}$ & 73 \\
\hline
\end{tabular}

Real-time quantitative reverse transcriptase-polymerase chain reaction (qRT-PCR) and 7500 Software v2.0.6, Applied Biosystem, were used to quantify the levels of mRNA. The following PCR thermal cycling protocol was adopted: heat to $95^{\circ} \mathrm{C}$ for $5 \mathrm{~min}, 50 \mathrm{cycles}$ of $95^{\circ} \mathrm{C}$ for $5 \mathrm{~s}$ and $60^{\circ} \mathrm{C}$ for $15 \mathrm{~s}$, then melting at $45^{\circ} \mathrm{C}-95^{\circ} \mathrm{C}$. The standard curve method was used; the slope ranged between -3.2 and -3.6 and the coefficient of determination, $\mathrm{R}^{2}$, was more than $99 \%$. This indicates near perfect amplification efficiency. To verify the specificity of the PCR product, a melt curve analysis was performed following qRT-PCR.

\subsection{Statistical Analysis}

Statistical Analysis: ANOVA (one way analysis of variance) and a Tukey test were used in assessing statistical differences among treatments. The accepted statistical significance was at a 5\% level, and Graph Pad Prism was used in its analytical evaluation. The presented results were in the form of a mean ( \pm standard error of mean). 


\section{Results}

\subsection{NECA Did Not Stimulate BCL2 mRNA Expression}

No significant change occurred in BCL2 mRNA gene expression when $10 \mu \mathrm{M}$ of the adenosine analogue NECA was incubated in L6 one-week-starved skeletal muscle cells for one hour (Figure 3).

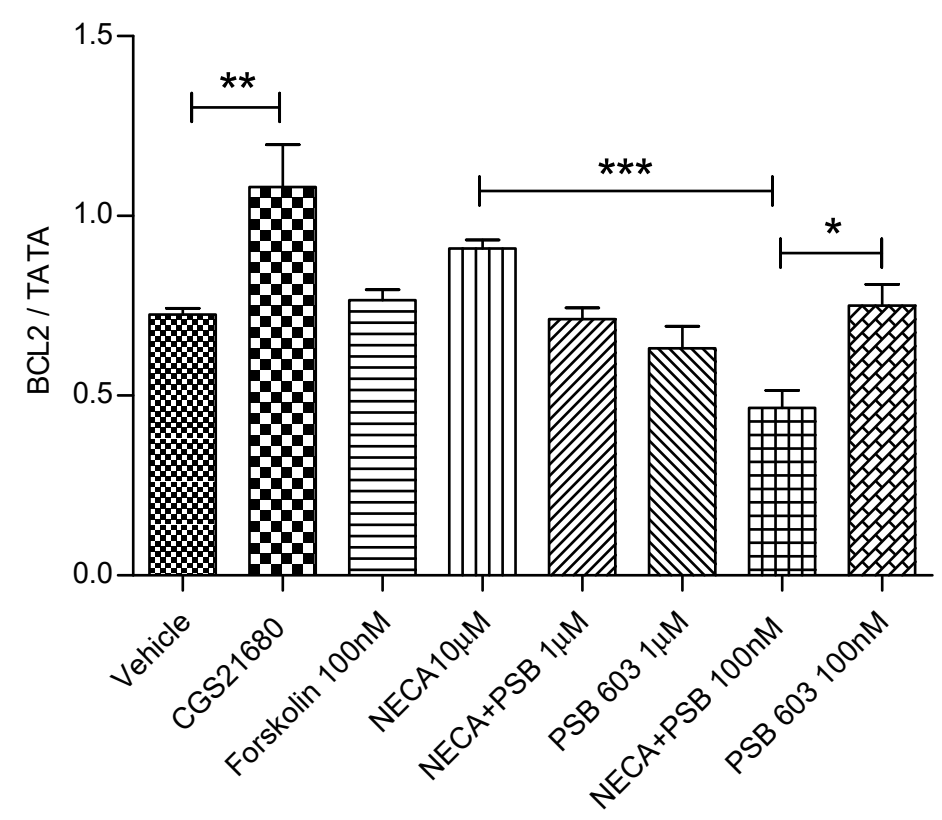

Figure 3. Effects of NECA, CGS21680, and PSB 603 on the gene expression of BCL2 messenger RNA (mRNA) in rat L6 skeletal muscle myotubes using charcoal serum. * denotes $p<0.05$, ** denotes $p<0.01$ and $^{* * *}$ denotes $p<0.001$. Data were analyzed with a one-way ANOVA test, then a Tukey test.

\subsection{CGS21680 Stimulated BCL2 mRNA Expression}

Incubation for one hour of L6 skeletal muscle cells starved for one week with $100 \mathrm{nM}$ of selective adenosine A2A receptor agonist CGS21680 produced a significant increase $(p<0.01)$ in mRNA gene expression of BCL2 (Figure 3).

\subsection{PSB 603 Did Not Significantly Affect mRNA Expression of BCL2}

mRNA expression of BCL2 was not changed by PSB 603 at a concentration of either $100 \mathrm{nM}$ or $1 \mathrm{uM}$. There was an interesting result, however, which was that treating cells that had been starved for one week with $10 \mu \mathrm{M}$ NECA $10 \mathrm{~min}$ after $100 \mathrm{nM}$ of PSB 603 produced a significant reduction $(p<0.01$ and $p<0.001$, compared with NECA and PSB 603 , respectively). The same effect was not observed when the concentration of PSB 603 used was $1 \mu \mathrm{M}$ instead of $1 \mathrm{nM}$, nor was the BCL2 mRNA expression level modulated by either PSB 603 or NECA alone (Figure 3).

Taken together, what these results show is the possibility that that adenosine A2 receptors could be functionally expressed receptors of adenosine receptors in skeletal muscle tissue, where mRNA gene expression levels for BCL2 are used as the functional readout.

\subsection{Role of cAMP Pathway in the Expression of BCL2}

The expression of BCL2 was not significantly increased by Forskolin (100 nM) (Figure 3), which differs from CGS21680.

\subsection{Insulin Failed to Modulate BCL2 mRNA Expression}

Following the incubation of one-week-starved L6 skeletal muscle cells with $100 \mathrm{nM}$ of insulin, no effect was encountered by the mRNA gene expression, thereby leading to insulin resistance in the paradigm that was employed (Figure 4). 


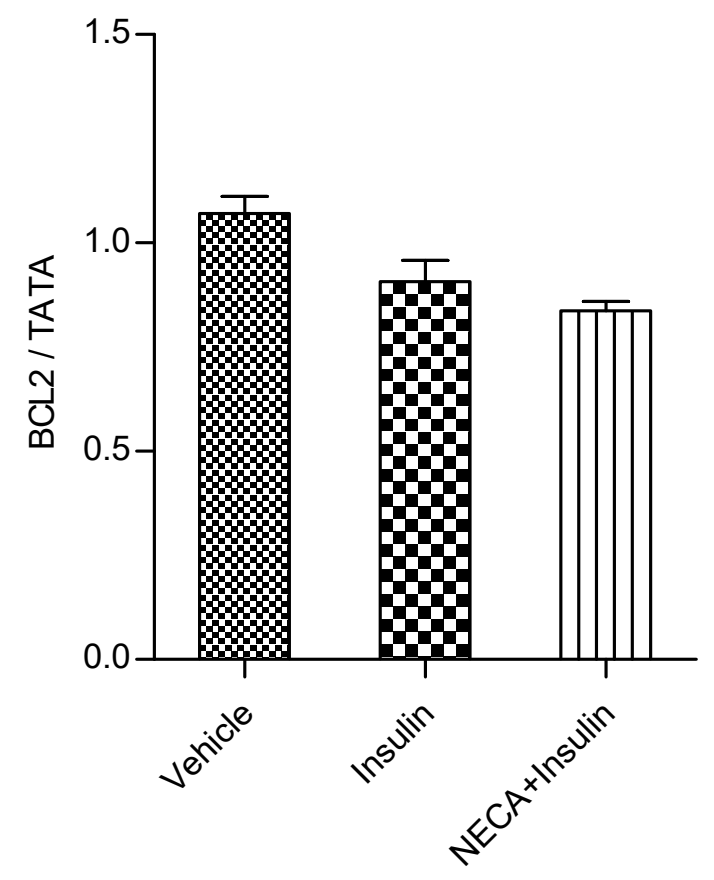

Figure 4. Effects of insulin and/or NECA on BCL2 messenger RNA (mRNA) gene expression, using charcoal serum, in rat L6 skeletal muscle myotubes. Data were analyzed with a one-way ANOVA test, then a Tukey test.

\subsection{NECA Did Not Modulate the Insulin Action in BCL2 mRNA Expression}

A one-week incubation of starved L6 skeletal muscle cells with $100 \mathrm{nM}$ of insulin for $10 \mathrm{~min}$, which was pre-treated for one hour by NECA $(10 \mu \mathrm{M})$, failed to produce a significant modulation of mRNA gene expression of BCL2.

\section{Discussion}

This study had seven principal findings. (1) mRNA gene expression of BCL2 was significantly increased $(p<0.01)$ by exposure for one hour to selective adenosine A2A receptor agonist CGS21680. (2) mRNA gene expression of BCL2 was not significantly affected by exposure for one hour to adenosine analogue NECA. (3) mRNA gene expression of BCL2 was not significantly affected by selective adenosine A2B receptor antagonist, PSB $603(100 \mathrm{nM}$ or $1 \mu \mathrm{M})$. (4) Baseline BCL2 mRNA gene expression was significantly reduced by the addition of NECA and $100 \mathrm{nM}$ (but not $1 \mu \mathrm{M}$ ) of PSB 603 when the PSB 603 was added to cells ten minutes before the NECA was added. (5) Expression of BCL2 was not significantly affected by Forskolin (100 nM). (6) Expression of BCL2 was not modulated by insulin $(100 \mathrm{nM})$. (7) In skeletal muscle cells, the action of insulin was not modulated by NECA.

Consistent with the original hypothesis of this study, the findings in the study for the first time showed that after CGS21680 treatment, BCL2 gene expression increased inside skeletal muscle cells, exposing them to a possible anti-apoptotic effect. Therefore, the potential increase in BCL2 protein expression could play a protective role against apoptosis, preventing skeletal muscle muscular damage [8]. In fact, the results showed that the adenosine A2A receptor's potential stimulation played a role in modulating the expression of the BCL2 gene that appears during CGS21680 treatment. The results also showed the adenosine A2A receptor agonists to be potentially useful drugs in the treatment of skeletal muscle injury. Adenosine A2A receptor agonists were potentially important apoptosis regulators $[9,13]$. Based on these results, it was therefore suggested that such adenosine A2A receptor agonists as CGS 21680 might be effective in treating a number of skeletal muscle regeneration diseases as well $[9,23]$. This study investigated the selective adenosine $\mathrm{A} 2 \mathrm{~A}$ receptor agonists' involvement in apoptosis modulation. The 
current investigation therefore introduced adenosine A2A agonists as potential agents for muscular dystrophy pharmacotherapy. Further research is required to achieve a complete understanding of apoptosis' molecular basis relating to adenosine receptors. This study begins to explain the mechanism by which adenosine A2A receptor agonist CGS21680 can prevent skeletal muscle apoptosis. Therefore, the receptors of adenosine could also represent novel pathways or targets for the pharmacological intervention in the process of apoptosis.

CGS21680, at the concentration applied in this current study, was regarded as a selective adenosine $\mathrm{A} 2 \mathrm{~A}$ receptor agonist $(\mathrm{Ki}=27 \mathrm{nM})$ [24]. However, some uncertainty surrounds the efficacy of CGS21680 targets due to the differences in various species' binding affinity of ligands for adenosine receptors and the lack of binding studies performed on rats. Of note, PSB 603 showed a strong affinity to adenosine A2B receptors but only a very weak affinity to three other subtypes of adenosine receptor. Adenosine A2B receptors show $>17,000$ times the selectivity of other adenosine receptors (Ki values: 0.553, >10,000, $>10,000$, and $>10,000 \mathrm{nM}$ for A2B, A1, A2A and A3 receptors, respectively) [25].

Experiments were conducted to investigate whether the adenylyl cyclase pathway contributes to the activation, in skeletal muscle cells, of the BCL2 transcription profile. Because of this, the present study used the adenylyl cyclase activator forskolin to help discover if the cAMP pathway plays a potential role in NECA-induced BCL2 mRNA gene expression in skeletal muscle. Previous studies showed that activation, by NECA, of adenosine A2B receptors in skeletal muscle increased the NR4A mRNA gene expression [19] and cAMP accumulation [14]. The findings in the current study support the notion of the cAMP pathway not playing a significant role in BCL2 mRNA gene expression induced by CGS21680, because Forskolin left BCL2 mRNA expression unchanged. Therefore, it is possible that CGS21680's effect occurs through G $\beta \gamma$ protein coupling or through transport. Of note, the concentration of forskolin $(100 \mathrm{nM})$ used in the present study is low. However, it is clear that the potency of forskolin $(100 \mathrm{nM})$ induces cAMP accumulation and increases the expression of downstream signalings (such as NR4A) in skeletal muscle cell systems, as was previously demonstrated $[14,19]$. Hence, the concentration of forskolin (100 nM) used in the present study is the same.

It was expected that treatment with insulin would contribute to cell death prevention by increasing the expression, in skeletal muscle tissue, of antiapoptotic genes, including BCL2. However, in this study, the skeletal muscle cell culture model was not given nutrients for one week (without FBS). During this week, insulin resistance was perceived in terms of inflammatory and metabolic effects. Previous studies found insulin to have a possible antiapoptotic effect $[26,27]$. For instance, streptozotocin-induced diabetic rats treated with insulin showed increased expression of BCL2 in the hippocampus. It was proposed that this was the antiapoptotic effect of insulin targeting a possible mechanism for hippocampal neuronal cell death induced by hyperglycaemia $[26,27]$. This study did not support this assertion, as it found that BCL2 expression was not modulated by insulin in skeletal muscle cells in one-week-starved rats. Starvation-induced insulin resistance in skeletal muscle cells and differences in tissue type might explain this.

Consistent with the current study, the adenosine A2A receptors represent a key mediator of adenosine function as an antiapoptotic agent. For example, one researcher reported that adenosine A2A receptor activation had a protective effect in small-for-size liver transplantation [16]. Another researcher also reported that A2A adenosine receptor activation was associated with attenuation of reperfusion lung injury and apoptosis through modulation of BCL2 expression and activation of extracellular signal-regulated kinases [13]. Other works highlighted the role of the adenosine A2B (pro-apoptotic) or the adenosine A3 (anti-apoptotic) receptors. For example, extracellular adenosine induced apoptosis of human arterial smooth muscle cells via adenosine A2B receptors [28]. Moreover, cytoprotective roles of adenosine $\mathrm{A} 3$ receptors were also reported in skeletal muscle ischemia and reperfusion injury [29]. 
The expression levels of A1, A2A, A2B and A3 receptors in this rat skeletal muscle cell line were previously reported [32,33]. In fact, it was interesting to examine other adenosine receptor ligands, in particular, for adenosine $\mathrm{A} 1$ and $\mathrm{A} 3$ receptors. However, the aim in this current study was to evaluate the adenosine A2 ligands only. This did not exclude the scientific importance of other adenosine receptors ligands. Of note, the rationale for the study of adenosine $\mathrm{A} 2$ receptors ligands (but not adenosine A1 and A3) was that previous research studies performed in this field showed positive responses to adenosine $\mathrm{A} 2$ receptor activation/inhibition, in particular, with CGS21680 and PSB 603, [18,20-22]. Actually, the aim of the present study was to investigate the potential role of highly selective adenosine A2 receptor ligands (CGS21680 and PSB 603) but not the potential role of adenosine A2 receptors themselves in skeletal muscle cells. Therefore, for the purpose of future work, it would be worthwhile to define the role of adenosine A2A receptor, using selective antagonists such as SCH58261 or SCH442416, and to investigate the modulation of BCL2 expression by those ligands. Moreover, given the interesting results obtained with different concentrations of the selective A2B antagonist, PSB 603, it would be worthwhile to define the role of adenosine $\mathrm{A} 2 \mathrm{~B}$ receptor and to test the modulation of BCL2 expression by a selective partial adenosine A2B agonist, BAY60-6583 [30].

One major concern was the concentrations of ligands used in this study. For example, while $100 \mathrm{nM}$ of CGS21680 was used, 10,000 nM of NECA was used. Actually, CGS21680 and NECA were almost equally potent at the A2A receptor, although NECA was also potent at A1, A2B and A3. Thus, in order to see a difference or similarity between CGS21680 and NECA, the concentrations used should be similar. However, the rationale of using $10,000 \mathrm{nM}$ of NECA was to examine the effect of PSB 603 as a selective adenosine A2B receptor antagonist, since NECA, a non-selective adenosine receptor agonist [31,32], was used in the current study at a concentration anticipated to activate A2B adenosine receptors $(10,000 \mathrm{nM})$. Moreover, in general, the adenosine A2B receptors had a lower affinity for adenosine [33].

\section{Conclusions}

The main findings of this study showed that BCL2 expression increased in response to CGS21680 inside skeletal muscle cells, exposing them to a possible anti-apoptotic effect. The peripheral increase of BCL2 played a protective role against apoptosis, preventing muscular damage. Further studies are encouraged to be performed in terms of crosstalk between the adenosine system and apoptotic pathways.

Funding: This study was supported mainly by the Abdul Hameed Shoman Foundation (Grant number 12/2015) and the Deanship of Scientific Research, Philadelphia University (Amman, Jordan).

Institutional Review Board Statement: Not applicable.

Informed Consent Statement: Not applicable.

Acknowledgments: The author would like to thank the Abdul Hameed Shoman Foundation for their generous financial support of this project. This study was performed at Philadelphia University and Cell Therapy Center-The University of Jordan-for around 12 months. The author would like to thank all staff members at the Cell Therapy Center-The University of Jordan, Amman, Jordan.

Conflicts of Interest: The author declares no conflict of interest.

\section{References}

1. Dirks, A.; Leeuwenburgh, C. Apoptosis in skeletal muscle with aging. Am. J. Physiol. Regul. Integr. Comp. Physiol. 2002, 282, R519-R527. [CrossRef] [PubMed]

2. Lee, G.; Lim, J.-Y.; Frontera, W.R. Apoptosis in young and old denervated rat skeletal muscle. Muscle Nerve 2017, 55, $262-269$. [CrossRef] [PubMed]

3. Dominov, J.A.; Kravetz, A.J.; Ardelt, M.; Kostek, C.A.; Beermann, M.L.; Miller, J.B. Muscle-specific BCL2 expression ameliorates muscle disease in laminin \{alpha\}2-deficient, but not in dystrophin-deficient, mice. Hum. Mol. Genet. 2005, 14, 1029-1040. [CrossRef] [PubMed] 
4. Zhang, Y.; Xu, M.; Zhang, X.; Chu, F.; Zhou, T. MAPK/c-Jun signaling pathway contributes to the upregulation of the antiapoptotic proteins Bcl-2 and Bcl-xL induced by Epstein-Barr virus-encoded BARF1 in gastric carcinoma cells. Oncol. Lett. 2018, 15, 7537-7544. [CrossRef]

5. Dominov, J.A.; Dunn, J.J.; Miller, J.B. Bcl-2 Expression Identifies an Early Stage of Myogenesis and Promotes Clonal Expansion of Muscle Cells. J. Cell Biol. 1998, 142, 537-544. [CrossRef] [PubMed]

6. Dominov, J.A.; Houlihan-Kawamoto, C.A.; Swap, C.J.; Miller, J.B. Pro- and Anti-apoptotic Members of the Bcl-2 Family in Skeletal Muscle: A Distinct Role for Bcl-2 in Later Stages of Myogenesis. Dev. Dyn. 2001, 220, 18-26. [CrossRef]

7. Davies, J.E.; Rubinsztein, D.C. Over-expression of BCL2 rescues muscle weakness in a mouse model of oculopharyngeal muscular dystrophy. Hum. Mol. Genet. 2011, 20, 1154-1163. [CrossRef]

8. Schöneich, C.; Dremina, E.; Galeva, N.; Sharov, V. Apoptosis in differentiating C2C12 muscle cells selectively targets Bcl-2-deficient myotubes. Apoptosis 2014, 19, 42-57. [CrossRef]

9. Apasov, S.G.; Chen, J.-F.; Smith, P.T.; Schwarzschild, M.A.; Fink, J.S.; Sitkovsky, M.V. Study of A2A adenosine receptor gene deficient mice reveals that adenosine analogue CGS 21680 possesses no A2A receptor-unrelated lymphotoxicity. Br. J. Pharmacol. 2000, 131, 43-50. [CrossRef]

10. Shalaby, A.; Rinne, T.; Järvinen, O.; Latva-Hirvelä, J.; Nuutila, K.; Saraste, A.; Laurikka, J.; Porkkala, H.; Saukko, P.; Tarkka, M. The Impact of Adenosine Fast Induction of Myocardial Arrest during CABG on Myocardial Expression of Apoptosis-Regulating Genes Bax and Bcl-2. Cardiol. Res. Pract. 2009, 2009, 1-6. [CrossRef] [PubMed]

11. Zhao, Z.Q.; Budde, J.M.; Morris, C.; Wang, N.P.; Velez, D.A.; Muraki, S.; Guyton, R.A.; Vinten-Johansen, J. Adenosine attenuates reper-fusion-induced apoptotic cell death by modulating expression of Bcl-2 and Bax proteins. J. Mol. Cell. Cardiol. 2001, 33, 57-68. [CrossRef] [PubMed]

12. Eisenstein, A.; Carroll, S.H.; Johnston-Cox, H.; Farb, M.G.; Gokce, N.; Ravid, K. An Adenosine Receptor-Krüppel-like Factor 4 Protein Axis Inhibits Adipogenesis. J. Biol. Chem. 2014, 289, 21071-21081. [CrossRef]

13. Rivo, J.; Zeira, E.; Galun, E.; Einav, S.; Linden, J.; Matot, I. Attenuation of reperfusion lung injury and apoptosis by A2A adenosine receptor activation is associated with modulation of bcl-2 and bax expression and activation of extracellular signal-regulated kinases. Shock 2007, 27, 266-273. [CrossRef]

14. Haddad, M. Adenosine Receptors Machinery and Purinergic Receptors in Rat Primary Skeletal Muscle Cells. Biomed. Pharmacol. J. 2014, 7, 383-398. [CrossRef]

15. Haddad, M. mRNA Expression of GPCRs in Rat Skeletal Muscle Tissues. Int. J. Biol. Pharm. Allied Sci. 2014, 3, $2506-2536$.

16. Tang, L.M.; Wang, Y.P.; Wang, K.; Pu, L.Y.; Zhang, F.; Li, X.C.; Kong, L.B.; Sun, B.C.; Li, G.Q.; Wang, X.H. Protective effect of adenosine A2A receptor activation in small-for-size liver transplantation. Transpl. Int. 2007, 20, 93-101. [CrossRef]

17. Haddad, M. Do CB1 Cannabinoid Receptors Regulate Insulin Signalling in Rat Primary Skeletal Muscle Cells? J. Phys. Pharm. Adv. 2013, 3, 277-291.

18. Haddad, M. Adenosine A2B Receptors-Mediated Induction of Interleukin-6 in Skeletal Muscle Cells. Turk. J. Pharm. Sci. 2017, 14, 19-28. [CrossRef] [PubMed]

19. Haddad, M. The Impact of Adenosine A2B Receptors Modulation on Nuclear Receptors (NR4A) Gene Expression. Biomed. Pharmacol. J. 2016, 9, 177-185. [CrossRef]

20. Haddad, M. The effect of NECA, CGS 21680, PSB 603 on fatty acid transport and oxidation in skeletal muscle cells. Int. J. Pharm. Sci. Res. 2016, 7, 4827-4838.

21. Haddad, M. The impact of adenosine A2B receptors on glycolysis and insulin resistance in skeletal muscle. Int. J. Pharm. Sci. Res. 2016, 7, 4917-4926.

22. Haddad, M. The impact of adenosine A2B receptors modulation on peroxisome proliferator-activated receptor gamma co-activator 1-alpha and transcription factors. Int. J. Pharm. Sci. Res. 2016, 7, 4762-4776.

23. Ramirez, S.H.; Fan, S.; Maguire, C.A.; Perry, S.; Hardiek, K.; Ramkumar, V.; Gelbard, H.A.; Dewhurst, S.; Maggirwar, S.B. Activation of adenosine A2A receptor protects sympathetic neurons against nerve growth factor withdrawal. J. Neurosci. Res. 2004, 77, 258-269. [CrossRef] [PubMed]

24. Klotz, K.N. Adenosine receptors and their ligands. Naunyn-Schmiedeberg's Arch. Pharmacol. 2000, 362, 382-391. [CrossRef] [PubMed]

25. Borrmann, T.; Hinz, S.; Bertarelli, D.C.; Li, W.; Florin, N.C.; Scheiff, A.B.; Muller, C.E. 1-alkyl-8-(piperazine-1-sulfonyl)phenylxanthines: Development and characterization of adenosine A2B receptor antagonists and a new radioligand with subnanomolar affinity and subtype specificity. J. Med. Chem. 2009, 52, 3994-4006. [CrossRef]

26. Jafari Anarkooli, I.; Sankian, M.; Vahedi, F.; Bonakdaran, S.; Varasteh, A.R.; Haghir, H. Evaluation of insulin and ascorbic acid effects on expression of Bcl-2 family proteins and caspase-3 activity in hippocampus of STZ-induced diabetic rats. Cell. Mol. Neurobiol. 2009, 29, 133-140. [CrossRef] [PubMed]

27. Soleymaninejad, M.; Joursaraei, S.G.; Feizi, F.; Anarkooli, I.J. The Effects of Lycopene and Insulin on Histological Changes and the Expression Level of Bcl-2 Family Genes in the Hippocampus of Streptozotocin-Induced Diabetic Rats. J. Diabetes Res. 2017, 2017, 1-9. [CrossRef]

28. Peyot, M.-L.; Gadeau, A.-P.; Dandré, F.; Belloc, I.; Dupuch, F.; Desgranges, C. Extracellular Adenosine Induces Apoptosis of Human Arterial Smooth Muscle Cells via A2b-Purinoceptor. Circ. Res. 2000, 86, 76-85. [CrossRef] 
29. Zheng, J.; Wang, R.; Zambraski, E.; Wu, D.; Jacobson, K.A.; Liang, B.T. Protective roles of adenosine A1, A2A, and A3 receptors in skeletal muscle ischemia and reperfusion injury. Am. J. Physiol. Heart Circ. Physiol. 2007, 293, H3685-H3691. [CrossRef]

30. Hinz, S.; Lacher, S.K.; Seibt, B.F.; Müller, C.E. BAY60-6583 Acts as a Partial Agonist at Adenosine A2B Receptors. J. Pharmacol. Exp. Ther. 2014, 349, 427-436. [CrossRef]

31. Castanon, M.J.; Spevak, W. Functional Coupling of Human Adenosine Receptors to a Ligand-Dependent Reporter Gene System. Biochem. Biophys. Res. Commun. 1994, 198, 626-631. [CrossRef] [PubMed]

32. Klotz, K.-N.; Hessling, J.; Hegler, J.; Owman, C.; Kull, B.; Fredholm, B.B.; Lohse, M.J. Comparative pharmacology of human adenosine receptor subtypes-Characterization of stably transfected receptors in CHO cells. Naunyn-Schmiedeberg's Arch. Pharmacol. 1998, 357, 1-9. [CrossRef] [PubMed]

33. Fredholm, B.B.; Chern, Y.; Franco, R.; Sitkovsky, M. Aspects of the general biology of adenosine A2A signaling. Prog. Neurobiol. 2007, 83, 263-276. [CrossRef] [PubMed] 